present value of leadless glazes to the trade at large. The tinie is not yet ripe for the drastic change proposed in their first recommendation.

Their third conclusion, "that the use of "raw' lead, i.e. ' unfritted' lead, as an ingredient of potters' glazes or colours, should be absolutely prohibited," is not one whit too strong. The experience of pottery manufacturers in this country and on the continent proves that such a course is possible in every section of the trade. Between the bisilicate of lead containing 65 per cent. of lead monoxide, used at Rörstrand (report, p. 20) and at Dresden (report, p. 25), and proved in the experience of those works to have abolished leadpoisoning, and the cumpound silicate discovered by Prof. Thorpe (see report, p. 32) containing 22 per cent. of lead-oxide, and stated to be insoluble in dilute acids, and therefore noninjurious, there would seem to be ample margin for all the potter's requirements. According to the evidence contained in the report, such compounds have been used for years, or might be used, without producing lead poisoning in those who work with them. Were the use of such of these compounds as are found to best answer the practical requirements of the various trades, made compulsory on every potter in this country, and the Factory Inspectors empowered to take samples from the dipping-tubs for examination in the Government Laboratory, the axe would indeed be laid to the root of this evil.

The report is to be commended to the careful consideration of every one interested in a great industry. The facts stated in it, speaking generally, admit of little or no dispute. From a careful consideration of its pages, one gathers the encouraging conviction that it contains information which will enable the question to be fairly and satisfactorily dealt with from the point of view of workman, manufacturer, and Home Office alike. Its second and third recommendations, worked in conjunction with the monthly medical examination of all workers, of whatever sex or age, who come in contact with any form of lead compound, and with the adequate protective provisions as regards ventilation, clothing, and cleanliness, now in force at all pottery works in this country, would put an end, within a reasonable time, to the gross evils of plumbism. It is to be hoped that the pottery manufacturers will rise to the situation, and show their willing. ness to adopt such of the recommendations contained in the report as are of practical value. ${ }^{\mathrm{I}}$ The existing state of things, at all events, cannot be allowed to continue.

\section{W. BuRTON.}

\section{IIECHANICAL ENGINEERING IN WAR. SHIPS.}

THE address delivered at the Institution of Mechanical Engineers on Thursday last, by the President, Sir William H. White, K.C.B., F.R.S., was a valuable statement of the part which mechanical engineering has played in the growth of our shipbuilding industry and the development of our mercantile marine during the past forty years. Mechanical engineering has intimate relations with all other branches of engineering, but with none has it been more closely associated than with shipbuilding in recent times; and in his address Sir William White indicated the directions in which the construction and working of ships have been influenced by it. He showed how the development of mechanical appliances for the equipment and working of ships during the last forty years is no less remarkable than the advance in the machinery used for shipbuilding. Nearly all steamships are now fitted with mechanical steering gear, mostly steam, in some instances hydraulic, and in a few recent ships electrical. The same motive powers are now used for working anchors and cables in steamships. Artificial ventilation is now very largely employed in many classes of ships, and especially in warships; electric lighting is becoming the rule; mechanical power is universally employed for pumping purposes in steamships; remarkable progress has been made in appliances for lifting coal and cargoes; and refrigerating machinery has led to the development of a new branch of the shipping industry, as well as added to the health and comfort of all who travel by sea. The advances in these and other directions were sketched by Sir William White, but the limitations of space prevent the publication of his address in full. The last section dealt with mechanical engineering in warships, and is here reprinted.

it The pottery manufacturers have already taken action in the direction indicated.

NO. I 540 , VOL. 60]
Mechanical Engineering in Warships.

The auxiliary machinery of warships necessarily has much in common with the corresponding machinery in merchant ships. There are, however, many special requirements arising from their armament and equipment as fighting machines, and hence it happens that in warships the applications of mechanical power reach their fullest development. Modern warships are sometimes styled "boxes of machinery," and the description is not inapt. The tendency is, in fact, to multiply machines, and to minimise manual labour to an extent which is not universally approved. On the other hand, with modern armaments and equipment, an extensive use of mechanical power is inevitable, and the expenditure of fuel on auxiliary services grows greater in proportion to that devoted to propulsion.

Ten years ago in a first-class battleship of 12,000 h.p. (maximum) for the propelling machinery, there were fifty auxiliary engines capable of indicating in the aggregate about 5000 h. p. if they all worked simultaneously-which they did not, of course. To-day, a similar statement would show a growth in the auxiliary power as compared with the propelling.

The multiplication of auxiliary services makes very serious demands upon the coal-supply of warships. Even in harbour the expenditure of coal is large on lighting, distilling, ventilation, air.compression, drilling with the heavy guns, and other services. From ro to 25 tons a day may thus be expended in a large battleship or cruiser of high speed. As warships cruise at low speeds and spend much time in harbour, it results that taking the year throtigh, fully as much coal is burnt for auxiliary services as for propulsion. Coal endurance being one of the most important factors in warship efficiency, facts such as these have tended to cause a doubt as to the wisdom of more widely extending mechanical appliances. It is pointed out that manual power with simple fittings, such as can be readily replaced if damaged in action, can compete with mechanical appliances in many directions; and that it is better to have larger crews in fighting ships, so as to provide a margin for inevitable casual ties, than to use the alternative of labour-saving machines liable to derangement or injury and not easily repaired in action. The practical solution of the problem clearly lies in the due proportion being found between manual and mechanical appliances.

Gun construction in its modern form is largely dependent upon mechanical engineering. Your past-Presidents, Lord Armstrong and the late Sir Joseph Whitworth, were famous as mechanical engineers before they undertook the design and manufacture of guns. In this Address, however, the story of progress from the smooth-bore cast-iron 68-pr., weighing $95 \mathrm{cwts}$, to the r ro-ton breech-loading rifled gun, firing I $800-1 b$. projectiles, can find no place. Nor can more than a brief glance be taken at the interesting work done by the mechanical engineer in regard to appliances for mounting, working, and loading modern guns, supplying the ammunition, and securing rapidity and accuracy of fire with a minimum of labour.

Anyone who will study the breech mechanism and mounting of a hand-worked quick.firing gun will discover a triumph of mechanical engineering over a very special and difficult problem.

Take, for example, a 6-inch quick-firing gun of the latest naval pattern. The gun weighs about 7 tons, fires Ioo-lb. projectiles, with a muzzle velocity of nearly 2800 feet per second, and an enersy of 5370 foot-tons, corresponding to a penetration of 22 inches of wrought iron. Its breech mechanism is so devised that four or five aimed shots can be fired per minute. Its mounting is so arranged that the gun can be easily trained, elevated or depressed by one man. The great energy of recoil is perfectly controlled, and the crew numbers only four or five men. If such a gun is compared with the 68-pr. smooth-bore muzzle loader, mounted on a wood truck carriage with rude arrangements for elevating, and still ruder for training and controlling recoil, one has a striking illustration of the progress made in forty years with hand-worked guns.

When one passes to heavier guns worked by mechanical power, a still greater contrast appears. The I lo-ton gun of 161 inches calibre has charges of $960 \mathrm{lbs}$. of powder and $1800-1 \mathrm{~b}$. projectiles. Fired with a velocity of 2100 feet per second, three projectiles have an energy of 54,000 foot-tons with an estimated penetration of 37 inches of wrought iron. Obviously, manual power alone was unequal to working such guns. The mechanical engineer has devised suitable machinery which enables pairs of guns, mounted in a thickly armoured turret, to be 
loaded, trained, elevated, and clepressed with ease and comparative rapidity under the guidance of a few men. Mr. George Rendel was one of the first, as well as one of the most successful, workers in the design of mechanical appliances for working heavy guns by hydraulic power. Messrs. Armstrong have from the first taken a leading position in this class of work. Messrs. Whitworth, and, in more recent times, Messrs. Vickers, have also undertaken it on a large scale. Hydraulic power finds most favour in the Royal Navy. Abroad, electrical power is now extensively used. Pneumatic power has been employed in a few cases.

Improvements in gun-design and in explosives have resulted in an increased ratio of power to weight in the latest types of guns. As a result, in the latest completed battleships, guns of I2-inch calibre, weighing 46 tons, firing $850-1 \mathrm{~b}$. projestiles, with muzzle velocities of about 2400 feet per second, and energies of 33,000 foot-tons have been used instead of the 67-ton and $110-$ ton guns of early date. These reduced weights of charges and projectiles are more easily handled; and this fact, together with certain changes in the system of mounting, have enabled many of the operations of loading and working the guns to be performed by manual power as well as by hydraulic power. This duplication is obviously advantageous, and reduces greatly the risk of heavy guns being put out of action. There was a time when a return to guns of still smaller dimensions, capable of being worked exclusively by hand-power, was strongly advocated. It was urged that it was unwise to depend at all on mechanical power, because it might fail at a critical moment. Such arguments are now but little heard. Experience does not demonstrate that any serious risk of "breakdown" need be feared in mechanical appliances. Moreover, the advocates of manual power overlooked the fact that, supposing that system had been adopted, there must still remain in all modern mount ings and breech mechanisms many comparatively delicate parts, perhaps more liable to injury or derangement than the appliances which were condemned.

Steady improvement has been made in heavy gun mountings and in rapidity of fire. For example, with 12 -inch guns from two and a half to three minutes were formerly considered to be a reasonable interval between successive rounds; now that interval has been brought below one minute, when pairs of guns are loaded and fired. Loading has also been made possible with the guns in any position, whereas formerly the guns were brought to fixed hoists, and to a definite angle of elevation for loading. It is most interesting to watch the working of these heavy guns, by means of mechanisms controlled by a few men. All the operations are performed with rapidity and precision, from the moment projectiles and charges are moved from their stowing positions in shell rooms and magazines situated deep down in the holds, up to the time when they are rammed home in the gun, the breech closed and the gun made ready for firing. Then one sees the captain of the barbette or turret training or changing the elevation of the gun up to the instant when he fires by electricity, and the huge projectile is discharged.

Passing from guns to torpedoes, one finds a fresh example of the important work done by mechanical engineers. The inventor of the automobile torpedo, Mr. Whitehead, is an eminent member of the profession. The torpedo itself is a beautiful example of mechanical engineering. All the machinery con. nected with air compression and storage, all the arrangements for ejecting above or below water, involve skilful mechanical design. Nor is this all. From the introduction of the torpedo has sprung the necessity for special structural and defensive arrangements in warships, as well as the construction of the swift torpedo flotilla-boats, destroyers, gunboats and depot ships, whose performances are not merely remarkable, but suggestive of possibilities in regard to steam navigation at high speeds.

The smaller classes of boats using the locomotive torpedo have to be carried by warships. They weigh, fully equipped, 18 to 20 tons, or about three times as much as the heaviest load ordinarily dealt with in merchant ships by their own lifting gear. This has involved the design of special lifting appliances for warships. After long experience in the Royal Navy, the most suitable arrangement has been found to be a strong steel derrick carried by the mast, with powerful steam or hydraulic hoists working tackles which lift the boats and top the derrick. Winches or capstans are also used in some instances for swinging the derricks. Admiralty specifications require that the lifting gear shall be capable of dealing with a load of about 18 tons lifted by a single wire rope, as well as with a load of 9 tons raised 30 feet per minute. In one ship, the Vulcan, built as a torpedo depot ship and boat carrier, instead of derricks two powerful hydraulic cranes are fitted. She carries six steel torpedo boats, 60 feet long and of 16 knots speed, besides sixteen other boats, some of large size. The total weight of these boats is 150 tons, and they are placed 27 feet above water. The two cranes and their gear weigh 140 tons; the tops of the cranes are 55 feet above water. It required careful designing to meet such exceptional conditions satisfactorily and to produce a stable and seaworthy ship. She has now been many years on service and has a good reputation.

Besides these special boat-lifting appliances, warships com. monly have special coal-hoists, transporters and other gear for the purpose of accelerating the taking of coal on board. Rapidity in coaling must be cf great importance in time of war, and keen competition between ships in the various squadrons as to the rates attained have led to great improvements in details of gear, as well as to remarkably rapid coaling becoming the rule in the Royal Navy. Recently, at Gibraltar, the Majestic took on board Iozo tons of coal in 6 hours and 10 minutes-a very fine performance.

All the larger ships in the Royal Navy have engineers" work shops fitted with a considerable number of machine-tools, driven by power, and of sufficient size to deal with ordinary repairs. The Vulcan is a special vessel in this sense also, as she has an exceptionally well-equipped workshnp, a small foundry and a hydraulic press for forgings. For repairs of the boats she carries, or for those of torpedo boats and destroyers in company, or for certain repairs to ships of the fleet to which she is attached, the Vulcan has been found most useful. Besides being a foating factory and a boat carrier, she has a large torpedo and mining equipment, an electrical laboratory, and serves as a school of instruction for mining and torpedo work. In addition, she is a swift cruiser, with a fair armament and well protected. As an armed ship, she represents the fullest appli. cation of mechanical appliances afloat. Her construction was commenced in 1887 . Other navies have since imitated her.

Another Vulcan was fitted up as a floating factory to serve with the American fleet during the recent war. She was originally a merchant steamer, but is said to have proved of great service. Naval opinion seems to favour the use of vessels of this class with fleets. It is held, moreover, that no modern fleet can be considered to be complete unless the fighting ships are supplemented by ships specially equipped for distilling and storing fresh water, or carrying coals, ammunition and reserve stores.

\section{SATURN'S NEW SATELLITE.}

IN Harvard College Observatory Circular, No. 43, just received, Prof. E. C. Pickering gives the following detailed account of the discovery and observations of the new satellite of Saturn :- -

Nearly all of the astronomical discoveries made by the aid of photography have related to the fixed stars. In the study of the members of the solar system, the results obtained by the eye are generally better than those derived from a photograph. For many years it has been supposed that photography might be used for the discovery of new satellites, and in April I888 a careful study of the vicinity of the outer planets was made by Prof. William H. Pickering. Photographs were taken with the I3-inch Boyden telescope, with exposures of about one hour, and images were obtained of all the satellites of Saturn then known except Mimas, whose light is obscured by that of its primary. It was then shown that Saturn probably had no satellite, as yet undiscovered, revolving in an orbit outside of that of Enceledus, unless it was more than a magnitude fainter than Hyperion (Forty-third Report Harv. Coll. Obs., p. 8).

In planning the Bruce photographic telescope, a search for distant and faint satellites was regarded as an important part of its work, and accordingly plates for this purpose were taken at Arequipa by Dr. Stewart. A careful examination of these plates has been made by Prof. William H. Pickering, and by superposing two of them, A 3228 and A 3233 , taken August 16 and 18 , I 898 , with exposures of $120 \mathrm{~m}$., a faint object was found which appeared in different positions on the two plates. The same object is shown on two other plates A 3227 and A 3230, taken 